\title{
The impact of fluoroscopic confirmation of thoracic imaging on accuracy of thoracic epidural catheter placement on postoperative pain control
}

This article was published in the following Dove Press journal: Local and Regional Anesthesia

\author{
Tabish Aijaz' \\ Kenneth D Candido ${ }^{1-3}$ \\ Utchariya Anantamongkol' \\ Gleb Gorelick ${ }^{4}$ \\ Nebojsa Nick Knezevic ${ }^{1-3}$ \\ 'Department of Anesthesiology, \\ Advocate Illinois Masonic Medical \\ Center, Chicago, IL, USA; '2Department \\ of Anesthesiology, University of \\ Illinois, Chicago, IL, USA; ${ }^{3}$ Department \\ of Surgery, University of Illinois, \\ Chicago, IL, USA; ${ }^{4}$ Department of \\ Radiology, Advocate Illinois Masonic \\ Medical Center, Chicago, IL, USA
}

\begin{abstract}
Background: Thoracic epidural analgesia (TEA) provides superior postoperative pain control compared to parenteral opioids after major thoracic and abdominal surgeries. However, some studies with respect to benefits of continuous TEA have shown mixed results. The purpose of this study was to determine the rate of successful TEA catheter insertion into the epidural space using contrast fluoroscopy and the impact of placement location on postoperative analgesia and opioid use.
\end{abstract}

Patients and methods: After Advocate health care institutional review board approval, we conducted a prospective, open-label, single intervention study on patients undergoing thoracic or upper abdominal surgery. A thoracic paramedian epidural approach and a loss of resistance to saline technique were used to place an epidural catheter above the T11 level and fluoroscopic images with injected contrast were taken to locate the catheter tip in the epidural space.

Results: Twenty-five subjects were included in the study, of which 3 catheters (12\%) were not identified as being in the epidural space. We found an average difference of 1.5 vertebral levels between clinical and radiological assessments of catheter tips. Thirteen catheters $(52 \%)$ were more than 1 vertebral level away from the clinically assessed level. No significant difference was found in the pain scores at 1, 24, and 48 hours after surgery between patients with correct versus incorrect catheter placement. Less opioids were used in the correct catheter placement group at 24 hours (256 morphine milligram equivalent [MME] vs $201 \mathrm{MME}$ ) and at 48 hours after surgery (250 MME vs $173 \mathrm{MME}$ ), but it was not statistically significant ( $p=0.149$ and $p=0.068$, respectively).

Conclusion: Improvement in assuring success in the technique for TEA catheter placement following major thoracic or upper abdominal surgery exists, for which contrast-enhanced fluoroscopy might be a promising solution.

Keywords: postoperative analgesia, epidurogram, thoracic epidural analgesia, neuraxial

\section{Introduction}

Thoracic epidural analgesia (TEA) has become a key tool to use in postoperative pain control after major thoracic or upper abdominal surgery. ${ }^{1,2}$ There is an extensive amount of evidence from several randomized control trials (RCTs) showing that TEA provides better postoperative analgesia after both thoracic and upper abdominal surgeries in comparison with intravenous (IV) opioids. ${ }^{3,4}$ Epidural analgesia has also shown to be superior to IV opioid analgesia in terms of intermediate- to longterm outcomes such as cardiac events, respiratory complications, faster recovery of bowel function, length of hospitalization, and prevention of chronic postsurgical
Correspondence: Nebojsa Nick Knezevic Department of Anesthesiology, Advocate Illinois Masonic Medical Center, 836 W. Wellington Ave. Suite 48I5, Chicago, IL 60657, USA

Tel +I 7732965619

Fax +I 7732965362

Email nick.knezevic@gmail.com 
pain..$^{5-9}$ Despite the high success rates of TEA in providing superior postoperative analgesia, concerns have been raised about the inclusion of TEA as a standard of care treatment in the postoperative recovery phase after major thoracic or abdominal surgery. ${ }^{10-13}$ Critics of TEA point out to the fact that its published failure rate ranges between $25 \%$ and $32 \%$, which is exceedingly high. ${ }^{13-15}$

It is important to distinguish between the primary and the secondary failure of TEA due to catheter migration. Primary failure occurs due to improper catheter insertion at the desired location into the epidural space, causing a failure of adequate postoperative analgesia. ${ }^{16,17}$ It can be due to the failure of catheter insertion into the epidural space or insertion of the epidural catheter at a vertebral segment differing from the clinically desired level. ${ }^{18} \mathrm{Sec}-$ ondary failure refers to the failure of analgesia from TEA after successful catheter insertion into the epidural space at the correct vertebral level. ${ }^{15,19}$ It has been reported by multiple studies that the rate of TEA failure varies between $20 \%$ and $30 \% .^{14-17}$ The rate of primary failure of catheter insertion into the thoracic epidural space has been reported to be $15 \%-24 \%$ which makes up about half of the failed cases. ${ }^{20-24}$ Moreover, during the last decade, publications of several case reports on rare but potentially fatal complications have raised some serious concerns regarding the benefits versus risks of the use of TEA. ${ }^{25-29}$ Several investigators have advocated for more research before expanding the use of continuous TEA for enhancing postoperative recovery. ${ }^{30-32}$

Traditionally, TEA is performed using percutaneous anatomical landmarks with no recommendations for imaging confirmation after catheter insertion. ${ }^{33}$ We believe that the majority of the clinical trials conducted to establish the benefits of TEA after major abdominal or thoracic surgery were based on the premise that catheter placement into the thoracic epidural space has a success rate of $100 \%$. This assumption may have resulted in an underperformance of TEA when compared to other analgesic modalities. ${ }^{34}$ In the past, techniques such as electrophysiological stimulation and pulsatile pressure waveform used to confirm the proper catheter placement in epidural space, demonstrated better outcomes. ${ }^{35}$ Fluoroscopic imaging is another such technique which has been used to confirm the placement of a catheter into epidural space. The purpose of this study was to determine the accuracy of catheter insertion in the thoracic epidural space by using fluoroscopic imaging with contrast injection, to confirm the presumed level of the tip of catheter and the effects of the level of the catheter tip location on pain scores, including the amount of opioid used within the first 48 hours following the surgery.

\section{Patients and methods}

\section{Selection criteria}

Patients undergoing thoracic or upper abdominal surgery were recruited for the study if they met the following criteria: patients aged 18-80 years, those undergoing thoracic surgery that is thoracotomy, thoracic aortic aneurism repair, thymectomy, or upper abdominal surgery (ie, esophagectomy, gastrectomy, pancreatectomy, hepatic resection, open cholecystectomy, abdominal aortic aneurism repair, hemicolectomy, total colectomy, and abdomino-perineal resection). Patients with the following preexisting conditions were excluded from the study: severe aortic valve stenosis, active neurologic disease, allergy to lidocaine or bupivacaine, allergy to iodine-based contrast agents, cutaneous disorders at the epidural insertion site, impaired preoperative coagulation status, and pregnancy. Written informed consent was obtained from all the patients after extensive discussion of the purpose of the study and the potential risks and benefits involved. The study was approved by the Advocate Healthcare Institutional Review Board after undergoing full review. This study is registered at clinicaltrials.gov (NCT 01764932).

\section{Technique of thoracic epidural placement}

The thoracic epidural catheter insertion was performed as an inpatient procedure in the preoperative holding area under sterile conditions by board-certified anesthesiologists who have pain management fellowship training and certification via the American Board of Anesthesiology added qualifications in pain medicine. Standard anesthesia procedures were conducted before the epidural procedure; a time-out was performed, IV access was obtained, monitors placed, oxygen administered, and sedative and analgesic drugs were used for premedication. Due to the extreme caudal angulations of the thoracic spinous processes between T4 and T9, a conventional midline approach to the thoracic epidural space may be difficult. ${ }^{36}$ A paramedian approach was used to insert the Tuohy needle above the T11 vertebral level. ${ }^{37}$ Following sterile preparation and draping of an appropriate thoracic level, the skin was anesthetized using 1\% lidocaine plain via a 25-gauge, 1.59 -cm-long hypodermic needle. Then a 17-gauge 8.89-cm Tuohy needle with the bevel-directed cephalad was introduced perpendicular to the anesthetized skin $\sim 1 \mathrm{~cm}$ lateral to the spinous process of the targeted segment and was advanced until the ipsilateral lamina or medial transverse process was contacted. We guided our needle into 
the epidural space at the appropriate thoracic level by using percutaneous surface anatomic landmarks. The prominent C7 spinous process, the scapular spine (T3), and the inferior border of the scapula (T7) are useful landmarks to approximate the puncture site to the intended segment. ${ }^{38}$ The needle was then withdrawn slightly and re-advanced medially without a change in cephalo-caudal direction. When bone was no longer contacted and the depth exceeded the depth previously noted, the epidural needle stylette was removed. The epidural space was entered using a hanging drop technique and was confirmed using the loss of resistance to saline technique using a syringe and $5 \mathrm{~mL}$ normal saline solution.

Once the loss of resistance was obtained, a 19G FlexTip Plus (single open end hole) epidural catheter was threaded $3-5 \mathrm{~cm}$ into the epidural space and was secured using tegaderm and steri-strips. A $3 \mathrm{~mL}$ test dose of $1.5 \%$ lidocaine with 1:200,000 epinephrine was administered to rule out intravascular or intrathecal catheter placement. The patient was transferred to the operating room. Following the transfer, contrast medium such as $5 \mathrm{~mL}$ of Isovue ${ }^{\circledR}-300$ (iopamidol; Bracco Diagnostics, Princeton, NJ, USA) was injected through the catheter and fluoroscopic images were obtained and saved in the lateral and anterior-posterior projections. Fluoroscopic real-time and continuous pulsed imaging for 3 seconds was used to verify that no contrast had attained intravascular, subarachnoid, subdural, or intradiscal spread. Next, a bolus of $0.15 \%$ ropivacaine with $2 \mu \mathrm{g} / \mathrm{mL}$ fentanyl was administered for a total dose of $0.1 \mathrm{~mL} / \mathrm{kg}$ of ideal body weight. The patient was maintained on a postoperative infusion of $0.15 \%$ ropivacaine and $2 \mu \mathrm{g} / \mathrm{mL}$ fentanyl at a rate of $6-8 \mathrm{~mL} / \mathrm{h}$.

\section{Primary and secondary outcomes}

The primary outcome measure for this study was the success rate of thoracic epidural catheter placement. Secondary outcome measures included the postoperative numerical rating scale (NRS) pain score and total amount of opioid use in morphine milligram equivalent (MME) between patients with correct catheter placement (defined as difference of less than two vertebral segments between clinical and radiological assessments of catheter tips) and incorrect catheter placement (defined as differences of two or more vertebral levels between clinical and radiological assessment of catheter tips). Parameters for secondary outcomes were assessed at 1, 24, and 48 hours after the completion of surgery.

\section{Patient monitoring}

The patient was then monitored postsurgically for the use of opioid and non-opioid pain medications as an inpatient for the next 48 hours. Parameters recorded in this study included demographic characteristics (age, gender, height, weight), type of surgery, analgesic medications taken in last 24 hours, NRS pain scores at 1, 24, and 48 hours after surgery, which the patient rated from 0 to 10 (where $0=$ no pain and $10=$ worst possible pain); technical difficulty of the procedure on a numeric scale from 0 to 10 graded by the attending anesthesiologist (where 0 no difficulty, 1-3 mild, 4-6 moderate, and 7-10 severe difficulties); presumed intervertebral level of catheter tip assessed by the anesthesiologist using percutaneous anatomic landmarks during clinical examination and the direction in which the catheter was threaded; duration of surgery, opioid medications used during surgery (type and total dose); type of opioid medication used postoperatively and dose of opioid medication in MME according to Center for Disease Control Guidelines. ${ }^{39}$ All images were saved and then reviewed contemporaneously by an independent radiologist who assessed the placement of the catheter tip (epidural space, intrathecal space, intravascular, or other) and intervertebral level where the catheter tip was located.

\section{Statistical analysis}

The sample size estimated for this study $(n=25)$ was determined to detect a difference in postoperative analgesia between groups with successful and unsuccessful catheter placement at $p=0.05$ and power $=0.90$. Student's $t$-test for unpaired samples was used to compare the differences in pain scores between patients with correct and incorrect catheter placement. A $p$-value $<0.05$ was considered to be statistically significant. Statistical analysis was performed using SPSS software version 23.0 (IBM, Armonk, NY, USA).

\section{Results}

A total of 34 patients were initially screened for inclusion in the study, out of which nine were excluded from the study due to contrast allergy $(n=1)$, failure to obtain imaging immediately after catheter insertion $(n=6)$, difficulty in determining the catheter level on clinical assessment $(n=1)$, and difficulty in determining catheter level on radiological assessment $(n=1)$. Patients included in the study were further classified into groups as detailed in Figure 1.

We found an average difference of 1.5 vertebral levels between clinical and radiological assessments of catheter tips. Only seven catheters $(28 \%)$ were placed at the same vertebral level as believed by percutaneous assessment of anatomical landmarks, while two catheters $(8 \%)$ were placed within one segment away; 11 catheters (44\%) were placed two 


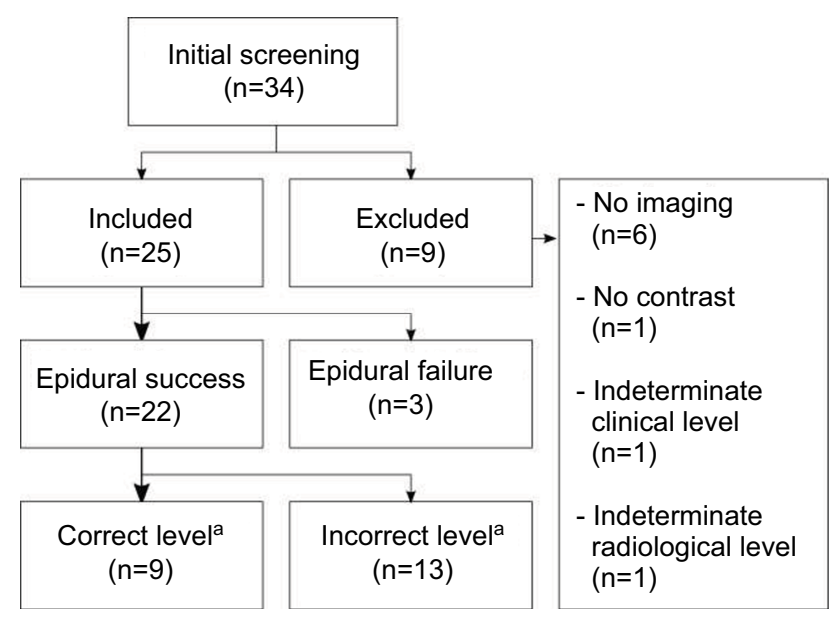

Figure I Selection and distribution of subjects.

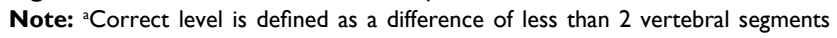
between clinical and radiological assessments of catheter tips, whereas incorrect catheter placement is defined as differences of 2 or more vertebral levels between clinical and radiological assessment of catheter tips.

segments away; two catheters (8\%) three segments away; and three catheters $(12 \%)$ were placed out of the epidural space completely despite clinically accepted loss of resistance to saline technique (Figure 2). We were unable to reliably identify the catheter tip in one patient using contrast fluoroscopy, who underwent computerized tomography (CT) scan of chest and abdomen during the immediate postoperative period for surgical reasons. Images from that CT scan were later used to successfully locate the catheter tip in the dorsal epidural space (Figure 3). We found no complications or secondary failures as a result of epidural catheter use in our study.

A total of 22 patients were included in the sub-analysis comparing patients with incorrect versus correct catheter placement (Table 1). There were no differences in the mean age, gender distribution, or body mass index in patients with incorrect catheter placement compared to those with correct catheter placement. In the incorrect catheter placement group, two patients received non-opioid IV analgesics, while in the correct placement group, three patients received non-opioid IV analgesics. In addition, all the incorrect catheter placements were caudal to the clinically determined level. No significant differences in difficulty in catheter placement were reported by the anesthesiologists (Table 1). We did not find significant differences between the patients with incorrect versus correct catheter placement in the numeric pain rating score postoperatively at 1 hour (3.50 vs 2.88 ; $p=0.668), 24$ hours ( 3.45 vs $4.00 ; p=0.572$ ), and 48 hours ( 3.55 vs 3.78; $p=0.232$ ). On the other hand, the use of opioids in patients with incorrect catheter placement was more when compared with that in patients with correct catheter placement at 24 hours (256 MME vs $201 \mathrm{MME}$ ) and 48 hours (250 MME

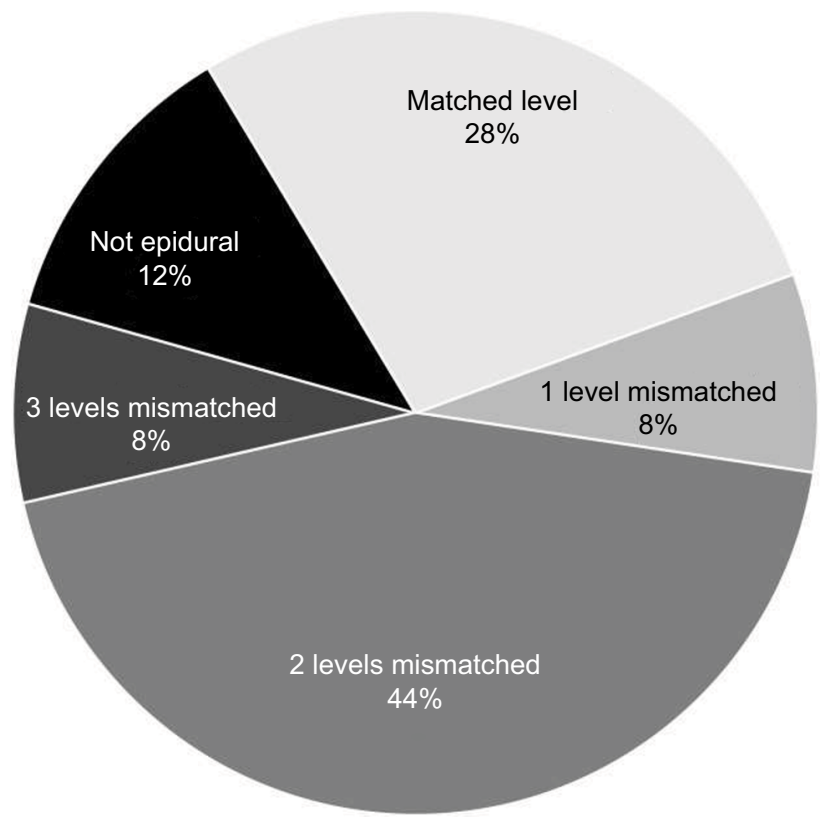

Figure 2 Degree of mismatch between clinical and radiological assessment.

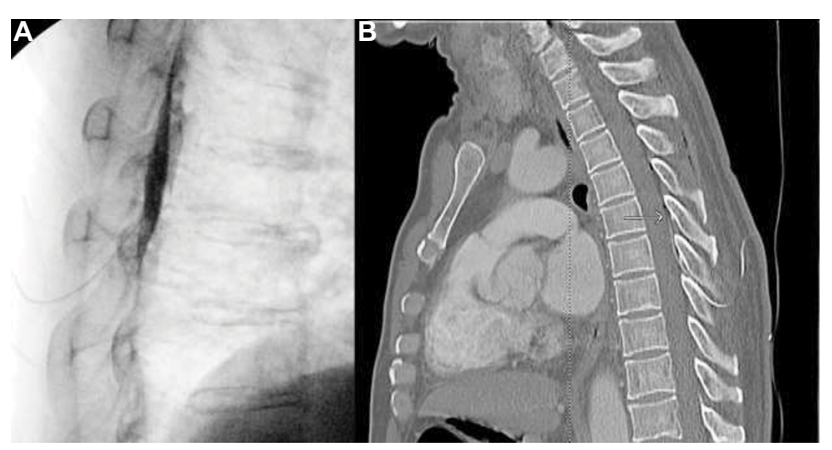

Figure 3 Thoracic epidural catheter with contrast shown on the $\mathrm{X}$-ray $(\mathbf{A})$ and computed tomography (CT) scan (B).

vs $173 \mathrm{MME}$ ), although we did not find it to be statistically significant ( $p=0.149$ and $p=0.068$, respectively).

\section{Discussion}

Until recently, the use of imaging to improve the rate of successful catheter insertion for TEA has not been explored by researchers. ${ }^{15,20,40,41}$ Very few studies have been published on post-placement confirmation of TEA using imaging, results of which have been mentioned in Table 2 . The primary failure rate of catheter insertion using the landmark technique was $6 \%-26 \%$ in these studies. In our study, about $12 \%$ of the subjects had primary failure of catheter insertion into the thoracic epidural space, which coincides with these results. Parra et al published the results of an RCT conducted at Dartmouth Medical Center, by comparing a fluoroscopic 
Table I Demographic distribution of patients with incorrect versus correct catheter placement

\begin{tabular}{|c|c|c|c|}
\hline Study characteristics & $\begin{array}{l}\text { Incorrect placement } \\
\text { Mean }( \pm S D) \\
(n=13)\end{array}$ & $\begin{array}{l}\text { Correct placement } \\
\text { Mean }( \pm S D) \\
(n=9)\end{array}$ & $\overline{p \text {-value }}$ \\
\hline Age, years & $58.00(16.78)$ & $58.33(8.34)$ & 0.957 \\
\hline Gender & & & 0.79 \\
\hline Male & 3 & 6 & \\
\hline Female & 10 & 3 & \\
\hline $\mathrm{BMI}, \mathrm{kg} / \mathrm{m}^{2}$ & $27.37(3.59)$ & $31.29(7.26)$ & 0.272 \\
\hline Procedure site & & & 0.57 \\
\hline Thoracic & 6 & 5 & \\
\hline Abdominal & 7 & 4 & \\
\hline Difficulty of catheter insertion & $2.8(3.1)$ & $3.8(3.2)$ & 0.6 \\
\hline Clinical level of epidural catheter & $7.8(1.6)$ & $7(\mathrm{I} .1)$ & 0.22 \\
\hline Radiological level of epidural catheter & $10(1.9)$ & $7.3(1.3)$ & $<0.01$ \\
\hline
\end{tabular}

Abbreviation: BMI, body mass index.

Table 2 Incidence of catheter placement out of epidural space using landmark technique in previous studies

\begin{tabular}{lllll}
\hline Study & Number of patients & Technique used & Type of study & Catheters placed out of epidural space \\
\hline Parra et al ${ }^{20}$ & $53^{4}$ & Fluoroscopy & RCT & $26 \%$ \\
Uchino et al ${ }^{45}$ & 83 & Fluoroscopy & Prospective & $6 \%$ \\
Motamed et al $\left.\right|^{15,40}$ & 125 & Computerized tomography & Prospective & $24.8 \%$
\end{tabular}

Note: *Catheter placed out of epidural space using landmark technique.

Abbreviation: RCT, randomized control trial.

method with a conventional loss of resistance method in patients undergoing thoracic surgery. ${ }^{20}$ Although they found no differences in postoperative pain scores, they did show a significant decrease in the postanesthesia recovery unit time, as well as length of hospitalization. These results provide further support for the hypothesis that the benefits of continuous TEA, particularly when compared to IV patient-controlled analgesia opioids, might be underreported due to a high rate of primary failure, which can be reduced with the use of contrast fluoroscopy. ${ }^{13,40}$ Parra et al were unsuccessful in finding statistically significant differences in the pain scores of patients with a successful placement of an epidural catheter. ${ }^{13}$ However, their analysis did not take into account the vertebral level at which the catheter tip was located. In our study, 52\% of patients with successful catheter insertion into the thoracic epidural space had the catheter tip more than two levels away from the clinically assessed levels. If we combined the rate of failed epidural catheter insertion and catheter placement at an incorrect vertebral level, it would account for two thirds of the thoracic epidural catheters placed.

The benefits of continuous TEA cannot be accurately ascertained if the catheter is not placed at the epicenter of the target dermatomal level, which will be trespassed primarily during the surgical incision and subsequent tissue manipulation..$^{33}$ Therefore, we set out to determine whether imaging confirmation for successful epidural catheter placement at the correct vertebra level has the potential to provide improved postoperative analgesia and a decreased use of postoperative opioids. ${ }^{34,42}$ Our study did not find any significant differences in patients who had correct catheter placement for pain scores at 1,24, and 48 hours postoperatively. Moreover, patients with correct catheter placement showed a trend toward decreased use of opioid medications, although it failed to reach statistical significance. One explanation for the failure to find significant differences with correct catheter placement in our study was that the assessment of pain scores is inherently variable between different subjects, while being more consistent in the same subject. This means that a large sample size is required to find a significant difference in pain scores. ${ }^{43,44} \mathrm{~A}$ clinical trial with a larger sample size might be useful to find the clinically relevant differences, which was not appreciable in smaller-scale studies.

Another possible explanation for finding no differences in postoperative pain control between correct and incorrect catheter placement is that the analgesic infusate reached the intended location regardless of the catheter tip location. The use of contrast fluoroscopy to determine the catheter level has been studied by only one retrospective study for patients 
undergoing thoracic surgeries, while no differences were found in the 24-hour pain scores and 24-hour opioid dose between the two groups. ${ }^{34}$ However, in the subgroup analysis, they found that patients who had a catheter placed more cranially or had increased cephalic-caudal dye spread had better postoperative pain control and required less opioids. These results support our hypothesis that patients with incorrect epidural catheter placement may receive adequate postoperative analgesia, while also highlighting the importance of identifying the correct catheter level at the time of insertion. Since it is unlikely that all patients with incorrect catheter placement will have uniform dye spread to reach the intended vertebral level (which is the epicenter of the expected nociception), the situation is more likely to result in failure of continuous TEA..$^{34,45}$

The use of pre-procedural ultrasonography for TEA catheter insertion has shown its value in postoperative analgesia in a recent study. ${ }^{46}$ Ultrasonography has shown utility in needle placement by statically (not dynamically) identifying the ligamentum flavum and dura mater. Nevertheless, catheter placement cannot be verified with this technique, which is a major limitation of this technique. ${ }^{46-48}$ Furthermore, the use of the CT scan to determine catheter placement in TEA has been studied by Motamed et al who were unable to correlate the vertebral level ascertained by CT scan with a clinically assessed dermatomal level. ${ }^{40}$ While we agree that a CT scan might not be ideal for routine use, due to larger radiation exposure, a case can be made for the use of CT scanning in patients for whom the results of conventional contrast fluoroscopy are unclear. ${ }^{42}$ In one of our cases, we encountered difficulty in interpreting the results of a fluoroscopic image. Incidentally, a postoperative CT scan was done on the same day for a surgical reason, and the results confirmed the location of the catheter tip. It was an interesting case, as it suggested that additional imaging such as CT scanning or ultrasound might occasionally be needed to identify the catheter tip location in the epidural space.

\section{Limitations}

Our research had certain limitations that should be addressed in future clinical trials. First, our study did not have a control group to compare the immediate postoperative analgesic outcomes of patients with successful primary TEA with those using IV opioid analgesia only. Second, the sample size made it difficult to find statistically significant differences among the two groups even if it were possible that these differences might have been clinically significant. Moreover, our study was aimed at the immediate postoperative pain relief and opioid use. Previous research works had demonstrated the benefit of TEA in reducing morbidity and length of hospital stay. ${ }^{5-9}$ Last, exposure of both patient and anesthesia provider to radiation has been a concern in contrast fluoroscopy, although we did not collect data on radiation exposure since establishing the safety of TEA was not our primary or secondary aim.

\section{Conclusion}

TEA has now become integral to standard postoperative recovery programs at several medical centers. ${ }^{2,49,50}$ We believe that contrast fluoroscopy can be incorporated as a standard part of TEA with little additional resources without affecting patient care or resulting in additional time required to insert the epidural catheter. Given the importance of the catheter tip location in providing effective analgesia, we suggest that further research comparing contrast fluoroscopy with traditional percutaneous anatomical landmark techniques should focus not only on the rate of successful catheter insertion into the epidural space but also on the catheter tip level within the epidural space.

\section{Acknowledgments}

We thank Alexei Lissounov (clinical research coordinator) and Shahram Nafisi (resident) for their help in data collection.

\section{Author contributions}

Tabish Aijaz and Utchariya Anantamongkol contributed to data analysis and interpretation and manuscript writing. Kenneth D Candido contributed to conception and design, clinical epidural placement, and manuscript writing. Gleb Gorelick contributed to conception and design and data interpretation. Nebojsa Nick Knezevic contributed to conception and design, data acquisition, data analysis and interpretation, and manuscript writing. All authors contributed toward data analysis, drafting and revising the paper and agree to be accountable for all aspects of the work.

\section{Disclosure}

The authors report no conflicts of interest in this work.

\section{References}

1. Wijeysundera DN, Beattie WS, Austin PC, Hux JE, Laupacis A. Epidural anaesthesia and survival after intermediate-to-high risk non-cardiac surgery: a population-based cohort study. Lancet. 2008;372(9638):562-569.

2. McIsaac DI, Cole ET, McCartney CJL. Impact of including regional anaesthesia in enhanced recovery. Br J Anaesth. 2015;115(2):ii46-ii56.

3. Nishimori M, Low JHS, Zheng H, Ballantyne JC. Epidural pain relief versus systemic opioid-based pain relief for abdominal aortic surgery [review]. Cochrane Database Syst Rev. 2012;7:CD005059. 
4. Park WY, Thompson JS, Lee KK. Effect of epidural anesthesia and analgesia on perioperative outcome: a randomized, controlled veterans affairs cooperative study. Ann Surg. 2001;234(4):560-569.

5. Rigg JRA, Jamrozik K, Myles PS, et al. Epidural anaesthesia and analgesia and outcome of major surgery: a randomised trial. Lancet. 2002;359(9314):1276-1282.

6. Adis Medical Writers. Minimize the risk of chronic pain after cardiac surgery by treating acute postoperative pain. Drugs Ther Perspect. 2015;31(7):229-232

7. Guay J, Nishimori M, Kopp SL. Epidural Local Anesthetics Versus Opioid-Based Analgesic Regimens for Postoperative Gastrointestinal Paralysis, Vomiting, and Pain After Abdominal Surgery: A Cochrane Review. Anesth Analg. 2016;123(6):1591-1602.

8. Zhang S, Wu X, Guo H, Ma L. Thoracic epidural anesthesia improves outcomes in patients undergoing cardiac surgery: meta-analysis of randomized controlled trials. Eur J Med Res. 2015;20(1):25.

9. Tiippana E, Nilsson E, Kalso E. Post-thoracotomy pain after thoracic epidural analgesia: a prospective follow-up study. Acta Anaesthesiol Scand. 2003;47(4):433-438.

10. Lee TWR, Kowalski S, Falk K, Maguire D, Freed DH, HayGlass KT. High spinal anesthesia enhances anti-inflammatory responses in patients undergoing coronary artery bypass graft surgery and aortic valve replacement: randomized pilot study. PLoS One. 2016;11(3): e0149942.

11. Svircevic V, van Dijk D, Nierich AP, et al. Meta-analysis of thoracic epidural anesthesia versus general anesthesia for cardiac surgery. Anesthesiology. 2011;114(2):271-282.

12. Low J, Johnston N, Morris C. Epidural analgesia: first do no harm. Anaesthesia. 2008;63(1):1-3.

13. Tran D, Zundert T, Aliste J, Engsusophon P, Finlayson RJ. Primary failure of thoracic epidural analgesia in training centers: the invisible elephant? Reg Anesth Pain Med. 2016;41(3):309-313.

14. Ready BL. Acute pain: lessons learned from 25,000 patients. Reg Anesth Pain Med. 1999;24(6):499-505.

15. Motamed C, Farhat F, Rémérand F, Stéphanazzi J, Laplanche A, Jayr C. An analysis of postoperative epidural analgesia failure by computed tomography epidurography. Anesth Analg. 2006(4):1026-1032.

16. Hermanides J, Hollmann MW, Stevens MF, Lirk P. Failed epidural: causes and management. Br J Anaesth. 2012;109(2):144-154.

17. Lirk P, Messner H, Deibl M, et al. Accuracy in estimating the correct intervertebral space level during lumbar, thoracic and cervical epidural anaesthesia. Acta Anaesthesiol Scand. 2004;48(3):347-349.

18. Leurcharusmee P, Arnuntasupakul V, Garza D, et al. Reliability of waveform analysis as an adjunct to loss of resistance for thoracic epidural blocks. Reg Anesth Pain Med. 2015;40(6):694-697.

19. Heinink TP, Baker BG, Yates VF, Addison DC, Williams JP. The effect of anaesthetist grade and frequency of insertion on epidural failure: a service evaluation in a United Kingdom teaching hospital. $B M C$ Anesthesiology. 2015;15(1):1-7.

20. Parra MC, Washburn K, Brown JR, et al. Fluoroscopic guidance increases the incidence of thoracic epidural catheter placement within the epidural space: a randomized trial. Reg Anesth Pain Med. 2017;42(1):17-24.

21. Arnuntasupakul V, Zundert T, Vijitpavan A, et al. A randomized comparison between conventional and waveform-confirmed loss of resistance for thoracic epidural blocks. Reg Anesth Pain Med. 2016;41(3): 368-373.

22. Chaney MA. How important is postoperative pain after cardiac surgery? J Cardiothorac Vasc Anesth. 2005;(6):705-707.

23. Svircevic V, Passier MM, Nierich AP, van Dijk D, Kalkman CJ, van der Heijden GJ. Epidural analgesia for cardiac surgery [review]. Cochrane Database Syst Rev. 2013;6:CD006715.

24. Peyton PJ, Myles PS, Silbert BS, Rigg JA, Jamrozik K, Parsons R. Perioperative epidural analgesia and outcome after major abdominal surgery in high-risk patients. Anesth Analg. 2003;96(2):548-554.
25. Liu SS, Carpenter RL, Mackey DC, et al. Effects of perioperative analgesic technique on rate of recovery after colon surgery. Anesthesiology. 1995;83(4):757-765.

26. Ho A, Chung DC, Joynt GM. Neuraxial blockade and hematoma in cardiac surgery estimating the risk of a rare adverse event that has not (yet) occurred. Chest. 2000;117(2):551-555.

27. Belani K, Montealegre-Gallegos M, Ferla B, Matyal R. Intrapleural placement of a thoracic epidural catheter in a patient with spinal stenosis. J Clin Anesth. 2016;35:195-197.

28. Amagasa S, Igarashi A, Yokoo N, Sato M. Intercostal bleeding that developed during thoracic epidural catheterization. J Anesth. 2008;22(2):197-198.

29. Gogarten W, Vandermeulen E, Aken H, et al. Regional anaesthesia and antithrombotic agents: recommendations of the European Society of Anaesthesiology. Eur J Anaesthesiol 2010;27(12):999-1015.

30. Lin TC, Huang YS, Lee SC, Ho ST, Cherng CH, Lu CC. Intrapleural misplacement of a thoracic epidural catheter in an anesthetized patient. Acta Anaesthesiol Taiwan. 2008;46(1):49-52.

31. Christie IW, McCabe S. Major complications of epidural analgesia after surgery: results of a six-year survey. Anaesthesia. 2007;62(4):335-341.

32. Cordone MA, Wu CL, Maceda AL, Richman JM. Unrecognized contralateral intrapleural catheter: bilateral blockade may obscure detection of failed epidural catheterization. Anesth Analg. 2007;104(3): 735-737.

33. Manion SC, Brennan TJ. Thoracic epidural analgesia and acute pain management. Anesthesiology. 2011;115(1):181-188.

34. Yeager MP, Bae EE, Parra MC, Barr PA, Bonham AK, Sites BD. Fluoroscopy-assisted epidural catheter placement: an exploratory analysis of 303 pre-operative epidurograms. Acta Anaesthesiol Scand. 2016;60(4):513-519.

35. Teng WN, Tsou MY, Chang WK, Ting CK. Eyes on the needle: identification and confirmation of the epidural space. Asian J Anesthesiol. 2017;55(2):30-34

36. O'Connor CJ. Thoracic epidural analgesia: Physiologic effects and clinical applications. J Cardiothorac Vasc Anesth. 1993;7(5):595-609.

37. Lai HC, Liu TJ, Peng SK, Lee KC, Luk HN, Lee SC. Depth of the thoracic epidural space in paramedian approach. J Clin Anesth. 2005;17(5):339-343.

38. Teoh DA, Santosham KL, Lydell CC, Smith DF, Beriault MT. Surface anatomy as a guide to vertebral level for thoracic epidural placement. Anesth Analg. 2009;108(5):1705-1707.

39. U.S Department of Health and Human Services. Calculating total daily dose of opioids for safer dosage. Georgia: Centers for Disease Control and Prevention, National Center for Injury Prevention and Control; 2016. Available from: https://www.cdc.gov/drugoverdose/pdf/calculating_total_daily_dose-a.pdf. Accessed October 6, 2017.

40. Motamed C, Chedevergne K, Deschamps F, Tselikas L, Jayr C. Contribution of low-dose computerized tomography with digital multiplanar reconstructions in thoracic epidurography and correlation with sensory block in postoperative analgesia. Anesthesiol Pain Med. 2016;6(5):e37577.

41. Yeager MP, Bae EE, Parra MC, Barr PA, Bonham AK, Sites BD Fluoroscopy-assisted epidural catheter placement: an exploratory analysis of 303 pre-operative epidurograms. Acta Anaesthesiol Scand. 2016;60(4):513-519.

42. Kuo WC, Kao MC, Tsou MY, Ting CK. In vivo images of the epidural space with two- and three-dimensional optical coherence tomography in a porcine model. PLoS One. 2017;12(2):e0172149.

43. Hirschfeld G, Zernikow B. Variability of "optimal" cut points for mild, moderate, and severe pain: neglected problems when comparing groups. Pain. 2013;154(1):154-159.

44. Gerbershagen HJ, Rothaug J, Kalkman CJ, Meissner W. Determination of moderate-to-severe postoperative pain on the numeric rating scale: a cut-off point analysis applying four different methods. Br J Anaesth. 2011;107(4):619-626. 
45. Uchino T, Hagiwara S, Iwasaka $\mathrm{H}$, et al. Use of imaging agent to determine postoperative indwelling epidural catheter position. Korean $J$ Pain 23(4):247-253.

46. Auyong, DB, Hostetter L, Yuan SC, Slee AE, Hanson NA. Evaluation of ultrasound-assisted thoracic epidural placement in patient undergoing upper abdominal and thoracic surgery: a randomized, double-blind study. Reg Anesth Pain Med. 2017;42(2):204-209.

47. Avramescu S, Arzola C, Tharmaratnam U, Chin KJ, Balki M. Sonoanatomy of the thoracic spine in adult volunteers. Reg Anesth Pain Med. 2012;37(3):349-353.
48. Teng WN, Tsou MY, Chang WK, Ting CK. Eyes on the needle: identification and confirmation of the epidural space. Asian J Anesthesiol. 2017;55(2):30-34.

49. Cushman D, Teramoto M, Curtis B, Lee DT, Marcolina A, McCormick $Z$. Does trainee involvement in fluoroscopic injections affect fluoroscopic time, immediate pain reduction, and complication rate? PMR. 2017;9(10):1013-1019.

50. King PM, Blazeby JM, Ewings P, et al. The influence of an Enhanced Recovery Programme on clinical outcomes, costs and quality of life after surgery for colorectal cancer. Colorectal Dis. 2006;8(6):506-513.
Local and Regional Anesthesia

\section{Publish your work in this journal}

Local and Regional Anesthesia is an international, peer-reviewed, open access journal publishing on the development, pharmacology, delivery and targeting and clinical use of local and regional anesthetics and analgesics. The journal is included in PubMed, and welcomes submitted papers covering original research, basic science, clinical studies,

\section{Dovepress}

reviews and evaluations, guidelines, expert opinion and commentary, case reports and extended reports. The manuscript management system is completely online and includes a very quick and fair peer-review system, which is all easy to use. Visit http://www.dovepress.com/ testimonials.php to read real quotes from published authors. 